\title{
Preface to the special issue dedicated to the 14th international workshop on global optimization held in Leiden, The Netherlands, September 18-21, 2018
}

\author{
André Deutz $^{1} \cdot$ Michael Emmerich $^{1} \cdot$ Yaroslav D. Sergeyev ${ }^{2,3} \cdot$ Iryna Yevseyeva $^{4}$
}

Received: 24 January 2021 / Accepted: 24 January 2021 / Published online: 19 February 2021

(c) The Author(s) 2021

This issue of the Journal of Global Optimization consists of a collection of research papers (see [1-9]) submitted to this special issue after the 14th International Workshop on Global Optimization (LeGO) organized by Leiden University. The LeGO workshop was co-organized by the International Society of Global Optimization and Leiden Institute for Advanced Computer Science and Mathematical Institute. The local chairs of the event were Michael Emmerich and André Deutz from Leiden Institute for Advanced Computer Science and Sander Hille from Mathematical Institute. One of the highlights of this workshop was a particular focus on the topic of multiobjective global optimization, and experts from this emerging topic in global optimization were particularly encouraged to send their contribution. Therefore, the conference featured a special track on multiobjective global optimization chaired and organized by Iryna Yevseyeva from De Montfort University, UK. The previous International Workshops on Global Optimization took place since 1985 in: Braga, Portugal, 2016; Málaga, Spain, 2014; Natal, Brazil, 2012; Tolouse, France; 2010; Skukuza, South Africa; 2008; Myconos, Greece, 2007; Almería, Spain, 2005; Santorini, Greece, 2003; Hanmer Springs, New Zealand, 2001; Firenze, Italy, 1999; Szeged, Hungary, 1995; Sopron, Hungary, 1985 and 1990.

The LeGO workshop was a very successful event that has attracted young researchers and brought them together in the program with senior specialists giving rise to discussions on new results and open research questions. The workshop was held in the Snellius building and Poortgebouw of Leiden University, in the historical Dutch university city of Leiden. Seventy participants of the Workshop presented and discussed their research results in the single track sessions. Five distinguished keynote speakers (Professors Sergiy Butenko, Kaisa Miettinen, Panos Pardalos, Yaroslav D. Sergeyev, and Antanas Žilinskas) gave inspiring plenary talks. Proceedings of the workshop edited by Michael T.M. Emmerich, André Deutz, Sander Hille, and Yaroslav D. Sergeyev have been published in 2019 as volume 2070 of AIP Conference Proceedings.

\footnotetext{
Michael Emmerich

m.t.m.emmerich@liacs.leidenuniv.nl

1 Leiden University, Leiden, The Netherlands

2 University of Calabria, Rende, Italy

3 Lobachevsky State University, Nizhni Novgorod, Russia

4 De Montfort University, Leicester, UK
} 
All the papers submitted to this special issue were regularly peer-reviewed. The Guest Editors greatly appreciate the hard work of the reviewers. Special thanks go to the Editorin-Chief of Journal of Global Optimization Professor Sergiy Butenko and the technical staff of Springer for their valuable support.

Open Access This article is licensed under a Creative Commons Attribution 4.0 International License, which permits use, sharing, adaptation, distribution and reproduction in any medium or format, as long as you give appropriate credit to the original author(s) and the source, provide a link to the Creative Commons licence, and indicate if changes were made. The images or other third party material in this article are included in the article's Creative Commons licence, unless indicated otherwise in a credit line to the material. If material is not included in the article's Creative Commons licence and your intended use is not permitted by statutory regulation or exceeds the permitted use, you will need to obtain permission directly from the copyright holder. To view a copy of this licence, visit http://creativecommons.org/licenses/by/4.0/.

\section{References}

1. Candelieri, A.: Sequential model based optimization of partially defined functions under unknown constraints. J. Global Optim. (2019). https://doi.org/10.1007/s10898-019-00860-4

2. Cavoretto, R., De Rossi, A., Mukhametzhanov, M.S., Sergeyev, Y.D.: On the search of the shape parameter in radial basis functions using univariate global optimization methods. J. Global Optim. (2019). https://doi.org/10.1007/s10898-019-00853-3

3. Jesus, A.D., Paquete, L., Liefooghe, A.: A model of anytime algorithm performance for bi-objective optimization. J. Global Optim. (2020). https://doi.org/10.1007/s10898-020-00909-9

4. Hladík, M., Kolev, L.V., Skalna, I.: Linear interval parametric approach to testing pseudoconvexity. J. Global Optim. (2020). https://doi.org/10.1007/s10898-020-00924-w

5. Kaliszewski, I., Miroforidis, J.: Cooperative multiobjective optimization with bounds on objective functions. J. Global Optim. (2020). https://doi.org/10.1007/s10898-020-00946-4

6. Lovison, A., Miettinen, K.: On the extension of the DIRECT algorithm to multiple objectives. J. Glob. Optim. (2020). https://doi.org/10.1007/s10898-020-00942-8

7. Reyes, V., Araya, I.: ABSTAYLOR: upper bounding with inner regions in nonlinear continuous global optimization problems. J. Global Optim. (2020). https://doi.org/10.1007/s10898-020-00878-z

8. Zheng, C., Calvin, J., Gotsman, C.: A DIRECT-type global optimization algorithm for image registration. J. Global Optim. (2020). https://doi.org/10.1007/s10898-020-00914-y

9. Žilinskas, A., Gillard, J., Scammell, M., Zhigljavsky, A.: Multistart with early termination of descents. J. Global Optim. (2019). https://doi.org/10.1007/s10898-019-00814-w

10. Homayouni, S.M., Fontes, D.B.M.M.: Production and transport scheduling in flexible job shop manufacturing systems. J. Global Optim. 74, 879-908 (2019)

11. Araya, I., Aliquintui, D., Ardiles, F., Lobo, B.: Nonlinear biobjective optimization: improving the upper envelope using feasible line segments. J. Glob. Optim. (2019). https://doi.org/10.1063/1.50900 07

Publisher's Note Springer Nature remains neutral with regard to jurisdictional claims in published maps and institutional affiliations. 